\title{
Small Talk
}

\section{Nanotechnology and Metaphor}

\author{
Joseph C. Pitt*
}

\section{Part 1 - Introduction}

The general topic I am addressing concerns the epistemological role of the use of metaphor in the philosophy of science. More specifically, I am concerned with the role metaphor plays in scientific and technological change. In the case in point, nanotechnology, I will explore the role of metaphor in changing our conception of the confirmation of the plausibility of theoretical notions. The basic idea is that metaphors either offer or suggest images that are meant to persuade one to change one's belief. ${ }^{1}$ Thus the confirmatory role is variable.

For a while now, I have been arguing against the tradition of perennial philosophy-the claim that there are universal, timeless questions to be solved and that there are in fact universal and timeless answers for these questions. In place of the perennial philosophy with its search for absolutes, I offer a Heraclitean philosophy of science that embraces change and seeks to understand the mechanisms behind changes. The goal is to produce a story that is itself a coherent account of what happened and why-helping us to understand why things are as they are at the present. This approach is rooted in history, but it rejects narrow or narrowly confined case studies in place of tracing and exploring scientific and philosophical problematics. ${ }^{2}$

A problematic is a source of worry and fascination that extends over a long period of time. Problematics are mostly linear clusters of problems. They come into being in a variety of ways - sometimes accidental, sometimes evolving out of other problems. The content may change as various individuals wrestle with it and as new and innovative technologies emerge, but there is a clear causal/social chain of events that can be traced. For example, when Galileo turned the telescope toward the heavens in 1609 and saw moons orbiting Jupiter, those observations threw the entire notion of an earth-centred universe

* Joseph C. Pitt is Professor of Philosophy at Virginia Tech. He is currently working on a book about the role of technological innovations, telescopes and microscopes, in scientific change.

${ }^{1}$ By "metaphor" I mean the use of a term with which we are familiar to characterize features of an object or situation with which we are not. Thus we talk about electrons orbiting the nucleus of an atom, having appropriated the term "orbit" from astronomy.

2 I first developed the notion of problematics in my 2007. The concept was elaborated in my 2001. (The first paper was originally presented at a conference in 1995 honoring Majorie Grene on the occasion of her $85^{\text {th }}$ birthday, but the volume did not appear until 2007.) 
into doubt. Galileo's observations allowed him to make the negative argument against the Aristotelian view, but he could not provide a replacement physics to make a positive argument for heliocentrism. ${ }^{3}$ His persistence in the face of controversy is remarkable, as are the social, political, and mathematical developments that form the context for his story, but what is at issue here is what Galileo offers in place of a physics: metaphor. ${ }^{4}$

To understand why Galileo was therefore willing to risk his career and life in promoting a new cosmology and scientific method, one has to understand the historical context. On this view then, the phrase "the Scientific Revolution" (contrary to certain efforts to deconstruct the phrase) identifies a problematic that takes over one hundred and fifty years to come to some sort of resolution. There was a lot going on during that time period and to understand that requires uncovering a lot of dots and then finding a way to connect them. Sometimes connecting the dots requires understanding where they came from, or, in other words, the influence of this or that on this person or that person. The history gets messy, which history is, and the story is constantly being revised as we learn more and more, which is as it should be. But the more we discover about why something happened and what its impact was or is, the more we should be amazed by the complexity of the dance and the fact that we can actually trace out a sense of progress. I would venture to guess that understanding complexity will give us a greater sense of intellectual security than basking in the light of false simplicity. But all of this concerns Galileo and on the surface may not appear to an assessment of the epistemic value of metaphor per se. So, let's move on with the understanding that we will return to these issues later.

\section{Part 2 - An Example of an Early Use of Metaphor to Facilitate Theory Change}

Eventually I want to look at the role of metaphor in extending knowledge, specifically the role of metaphor in the development of a language to talk about what is going on or what might be possible at the nanoscale. To place this in a context, I want to look at two examples that rely heavily on multiple metaphors to ascertain what, if any, light they ultimately shed on the vexing question of whether self-replicating nano-robots are possible. This is an important question because the possibility of self-replicating nanobots has also raised the spectre of run-away technology and all sorts of dire consequences.

In an earlier paper, "When is an image not an image?", I argued that we use metaphor to help us understand new theories and hypotheses about the world, when what is new is sufficiently novel and different from that with which we are

${ }^{3}$ See my 1992 for a fuller discussion of the structure of the Dialogue and Galileo's efforts to circumvent the problems he encountered defending Copernicus' view. While it is true that Galileo did not have a full physics, he did attempt to use the concepts of circular and relative motion to make his point. They simply weren't up to the job.

${ }^{4} \mathrm{My}$ thanks to Isaac Record for this formulation. I could not have said it better. 
familiar that, on the surface, it may appear impossible to gain access or understanding. Consider again, for example, Galileo's defence of the heliocentric theory. Two things to keep in mind here:

Neither Copernicus nor Galileo had a physics to explain how the earth could move-they were offering, at best, a different description of the structure of the solar system. There were many reasons in support of the new theory, but they were as much aesthetic as anything else. We will return to this issue below.

Replacing the geocentric view with the heliocentric one was for many also impossible to comprehend. Putting the physics aside, the centrality of the earth was absolutely crucial to the understanding educated folks in Western Europe at that time had of who they were. To see this you need to couple Aristotle's physical argument for the earth' central location with the theology deriving from Genesis, Book 1. From Aristotle we get both centrality and the sphericity of earth-earth is the heaviest of the elements-all four elements seek their natural place - earth, after the chaos coalesces at the centre since the heaviest element falls downward-and if earth falls downward from all possible directions, a sphere is the natural result. From Genesis we are told that God created Man in His image and gave him dominion over the earth. Put the two together and you find Man, in God's image, at the centre of God's universe with dominion over the earth-hence man is the centre of God's attention.

Move the earth out of the centre and it all falls apart. There is no evidence that God sees Man in any special light - the earth is just one of many planetsnothing special there, etc. In the immortal words of Anna Russell, "it all falls down." Aristotle's explanations of why the earth is where it is and has the shape it does are now inadequate.

So, what does Galileo do? He doesn't have a physics to explain how the earth can move. Somehow, however, he has to reassure people that they have not been rendered irrelevant. To overcome both problems he does two things:

He introduces a language that all the contestants use and can understand, giving them the illusion of sharing a common ground. That language is geometry. Most of Aristotle's physical arguments employ a form of conceptual argument: if this means this then this follows. Surprisingly, in his Dialogue on the Two Chief Systems Galileo does not try to refute Aristotle's account. He is much more subtle. Rather, he shows that Aristotle's arguments could be better put in the language of geometry.

Consider his opening volley. He starts by giving us Aristotle's familiar proof that the world is perfect in an attempt to lay the Peripatetics' grounds for refuting Copernicus's claim that the earth moves.

For, he (Aristotle) tells us, it is not a mere line, nor a bare surface, but a body having length, breath, and depth. Since there are only these three dimensions, the world, having these, has them all, and having the Whole, is perfect. (9) 
Galileo then continues:

To be sure, I much wish that Aristotle had proved to me by rigorous deductions that simple length constitutes what we call a line, which by the addition of breadth becomes a surface; that by further adding altitude or depth to this there results a body, and that after these three dimensions there is no passing farther-so that be these three alone, completeness, or, so to speak, wholeness is concluded. (910)

Here Galileo is simply appealing to the principles of Euclidean geometry and shortly he actually draws a diagram to illustrate his point. Throughout the rest of Dialogue he resorts to this technique-making the diagram, employing Euclidean geometry, the proof of one point after another.

The second move is simply ingenious. With no celestial physics at his command, he nevertheless offers as his crowning argument a pseudo geometric explanation that the earth moves. It is both a proof by elimination and a conditional proof. He argues that only by assuming the earth moves can we explain why there are tides - a most contentious problem at the time. As the earth turns on its axis the seas slosh the same way water in a barge does as the barge accelerates and slows down. That is the punch line-but the argument is loaded with geometric diagrams and lots of handwaving.

Galileo has compounded two techniques here-first, over the course of the book he has essentially legitimised appeals to geometry as a lingua franca. Second, he then turns to the metaphor of the barge carrying water from the mainland to Venice and the way the water sloshes back and forth to make his case for the tides, hence the earth moves, QED. The idea here is to extend something with which Galileo's contemporaries are familiar, the sloshing of water in a barge, to the unfamiliar, the earth in motion.

Does the proof really work? No. But the metaphor of the barge is highly compelling. It was readily understood by the educated lay person of the time. Using metaphors or analogies to make a point was fairly common at the time. Coupled with Galileo's pandering to his audience, convincing them that they can understand these sometimes complex geometric proofs-he both offers an explanation and reduces their fears. If we try to understand the epistemic punch of the metaphor of the barge, we have several options. Either Galileo offers a proof that compels us to change our minds on rational grounds or he is doing something else. Clearly it is something else, for, as already noted, the so-called proof fails. I am willing to argue, at this point, that, at best, the combination of the geometric machinations and the barge metaphor can be considered as an attempt at persuasion. On the other hand, Galileo probably believed he was doing more - this theory of the tides having been dear to him since 1595 (when 
he probably stole it from his friend Scarpi). But what he thought he was accomplishing and what he did accomplish are two different things.

\section{Part 3 - NANO - Do Mixed Metaphors and a Lot of Mathematics Constitute a Proof?}

A lot of scary stuff has been written about what could go on at the nano scale and the implications for us'ins here up top. One of the most controversial ideas put forth is Eric Drexlers' idea of self-replicating nano-robots-nanobots, which can in itself be considered a metaphor. Fear runs rampant especially among technophobes- since Drexler's nanobots are to be self-programming. What if these things gain some sort of autonomy and take over the world?! In a two page article in September 2001's Scientific American (a fairly safe place to offer this argument since its readership is fairly pro-science and technology), Nobel laureate Richard Smalley tried to put those fears to rest. He is not offering a defence of nanotechnology. Rather, he attempts to show that fears based on Drexler's scenario are unwarranted since Drexler's scenario can't occur according to Smalley. While his strategy does not completely map onto Galileo's, there are enough similarities to give us reason to take a close look at his argument and to see if he manages to achieve crowd control. Let me be clear from the start, I am on his side on this one-but I also want to make sure the case has really been made. What I will conclude is that Smalley and Galileo both employ what can be described as a political strategy designed more for persuasion that getting at the truth.

Smalley's account runs roughly like this:

1. love is like chemistry (metaphor \#1)_put two people together and there is a product that results. This is a case of intrinsic affinities.

2. chemical reactions, however are actually a lot more complicated than love, i.e., it is more complicated than just putting two atoms together and seeing what emerges. In the space, roughly one nanometer, within which the appropriate atoms are supposed to react, there are, in fact, many atoms, 12 to 15-engaged in a "three dimensional waltz" ( $2^{\text {nd }}$ metaphor).

3. one nanobot would not be useful-generating even a tiny amount of a product would take a solitary nanobot millions of years-lots of math now follows which I have to take on faith:

4. "Making a mole of something - say 30 grams, or about one ouncewould require at least $6 \times 10$ to the $23^{\text {rd }}$ bonds, one for each atom. At the frenzied rate of 10 to the $9^{\text {th }}$ per second it would take this nanobot $6 \times 10$ to the $14^{\text {th }}$ seconds - that is, 10 to the $13^{\text {th }}$ minuteswhich is $6.9 \times 10$ to the ninth days, or 19 millions." Pretty slow, eh? Pretty much like Galileo's proof for the tides, nay? 
5. But, if the nanobot could replicate itself and then if the two could replicate themselves we could have an army ( $3^{\text {rd }}$ metaphor) of nanobots at our command-and then they could work together and increase the rate of production and maybe the world of plenty would be possible.

6. But they could then also mutate ( $4^{\text {th }}$ metaphor) and get out of control reducing the world to "an undifferentiated mass of grey goo" $\left(5^{\text {th }}\right.$ metaphor) or simply eliminate the need for humans.

7. BUT-this is not possible for two reasons, given the already mentioned small space in which atomic reactions occur:

a. fat fingers (metaphor 6 ) and

b. sticky fingers (metaphor 7).

8. Fat fingers: because the arms of a nanobot must itself be made of atoms, there is an irreducible size problem. "There just isn't enough room in the nanometer-size reaction region to accommodate all the fingers of the manipulators necessary to have complete control of the chemistry."

9. Sticky fingers: "The atoms of the manipulator arms will adhere to the atom that is being moved. So it will be impossible to release this miniscule building block in precisely the right spot."

10. In conclusion, Smalley returns to his love theme and also to his waltz theme-neatly tying his first two metaphors together and then relating them to the nanobot theme:

Like the dance of love, chemistry is a waltz with its own step-slide-step in three-quarter time. Wishing that a waltz were a merengue-or that we could set down each atom in just the right place_-doesn't make it so."

Well, does Smalley's argument work? We have several metaphors at workseven at least_-and they don't obviously compliment each other-love, waltzes, nanobots, army, fat fingers and sticky fingers. The fingers can work togetherlove and waltzes are a stretch, and "army" stands out like a sore thumb. Let's spell out two of the metaphors in a bit more detail, love and sticky and fat fingers.

The love metaphor has to do with the way in which atoms are attracted to one another. According to Smalley it is not as simple as putting two people together. Put two people together and love develops. Put two atoms together and it isn't clear that anything will happen. Chemistry is about atomic affinities, some atoms bond more readily than others. But isn't that also the case with people? Just putting two people together doesn't guarantee love. On the other 
hand, Smalley's second point is that you just don't find two atoms in a space, you find several. Further, these several atoms are engaged in a waltz. He doesn't explain this, but what he seems to be suggesting is that the situation at the nanolevel is fairly unstable-the atoms are in constant motion, therefore no nanobot can be constructed. However, this is not an argument, it is a rhetorical sleight of hand suggested by the waltz metaphor.

If we turn to the metaphor of fat and sticky fingers we find more of the same. I think I know what he means by both. I try to play the piano. Often I just can't get my fingers between two black keys and I mutter "fat fingers". To me, "fat fingers" means there isn't enough room for me to get my fingers in there. For Smalley, "fat fingers" means something similar, ${ }^{5}$ essentially he is saying that whatever implement we use to manipulate the atoms at the nano level, it will be too large to fit the area and therefore we will not be able to control the atoms in the way we think we can. My problem with this argument is that it is not clear why the area is so confined. Smalley has not produced the rationale for thinking that we necessarily have the fat fingers problem.

When it comes to sticky fingers we face a more difficult issue. The "sticky fingers" metaphor is supposed to convey the following: atoms have a tendency to stick to one another; therefore when we use an implement to pick up an atom and deposit it elsewhere the atom will stick to the implement. It will not let go and, hence, we cannot really put it down, get another atom and put it next to it, continuing to build something. There are two problems here. First, this seems to go against the chemistry-isn't-love theme of the first Smalley metaphor. Second, we seem to have empirical evidence that shows we can in fact pick up an atom and deposit it where we want it. This evidence comes in the form of a picture two IBM researchers published showing the name IBM spelled out atom by atom. ${ }^{6}$

Then we have the razzle-dazzle quick math computation which I see as an effort both to prove his point about the amount of time it would take for a nanobot to accomplish anything, and as a way of establishing the scientific nature of the discussion-since the whole point of talking about chemistry in metaphorical terms is to make non-chemists think they understand what is going on-we also clearly need to establish our scientific credentials. The best way to do this is to appeal to the language of science: mathematics-even if we can't refute it, we know it is math and it therefore must be good. The problem is that as with many metaphors, it becomes very difficult to break the argument apart-each metaphor supports, as it were, a different premise and in each case this can, perhaps, be seen as the argument for the premise. It is not always a very good argument, as we have seen, but it can be persuasive.

\footnotetext{
${ }^{5}$ This is the beauty of using metaphors; they rely on what you think you understand it to mean based on your own experience, which may not be exactly what the author intended.

${ }^{6}$ In 1990, D.M. Eigler and E.K. Schweizer published a paper in Nature that included a photo of an image spelling out IBM, proving that atoms could be deliberately manipulated to form specific configurations using a scanning tunneling microscope.
} 
So, does the parallel hold up between Galileo and Smalley? Well, they both start with the familiar-Aristotle's method of proving things on the one hand and love, on the other hand. Then they both move to mathematics. Finally, they turn to new metaphors-barges and fat fingers. Galileo's geometrical argument for the tides fails - Smalley's math is probably correct, but on the key points he reverts completely to metaphors. It is not clear that Smalley's metaphors are strong enough by themselves to carry the day-consider the sticky fingers claim - if he is correct that we won't be able to place atoms where we want them, then how do we account for the IBM image? Likewise for the fat fingers claim. But it is unclear as to whether Smalley is appealing to genuine technical difficulties or engaging in a rhetorical strategy.

In closing we find ourselves with more problems than we can solve. Can metaphors be falsified by empirical data? Can metaphors function successfully as arguments? Galileo's metaphor of the barge fails, not because of empirical evidence, but because he just doesn't have a physics to support it. In Smalley's case it is not clear. While the IBM image seems to suggest that at least the sticky fingers metaphor fails, we have the problem of asking if the construction of a set of letters is in any way similar to the construction of nanobots and their hopedfor ability to construct various products. What seems clear to me is that to make headway on Smalley's "refutation" of Drexler, we need to understand the epistemic value of metaphor, what the criteria are for evaluating their rhetorical power, and how these criteria change over time. When we spell all this out we will find that our older notions of what constitutes evidence and confirmation must change in light of that new understanding. Philosophers for years have resisted crediting any genuine epistemic impact to rhetorical devices-with Popper rejecting a logic of discovery in which metaphors play a crucial role and the positivists concentrating solely on the logic of allegedly universal and unchanging concepts. This resistance is despite the fact that philosophers have used metaphors as far back as Heraclites (stepping in the same river twice) and Plato (the cave). But if there is an epistemology of metaphor, those positions must be re-examined. This is not beating a dead horse. Well, yes, at least these two horses, Popper and Positivism, are dead. It is the perennial philosophy I am after. What STS has forced Philosophy of Science to recognize is that there is a changing plurality of epistemic concepts appropriate to the analysis of science and this enlarges the philosophical field of analysis. In this sense the problematic of devising an appropriate normative epistemological account of science must change to accommodate rhetorical devices scientists as well as philosophers use and the contexts in which they use them. Thus, sometimes the audience is other scientists-as in Smalley's Scientific American article, and sometimes the educated public, as in Drexler's book - which yields the interesting question of whether an undermining metaphor needs to be directed to the same audience to be effective. That is, does Smalley's metaphors of fat and sticky fingers appeal 
to or even make sense to the folks who reacted to Drexler's nanobots? This, interestingly enough, is a philosophical question that needs empirical work.

In closing I want to end with a simple question: is the philosophical problematic regarding scientific epistemology changing by accommodating the social, and if so, what does this mean for the perennial philosophy? My guess is that it is and it strikes a mortal blow to the misguided search for eternal answers.

\author{
JOSEPH C. PITT \\ Philosophy Department \\ Virginia Tech \\ 229B Major Williams Hall \\ Blacksburg, VA 24061 \\ U.S.A. \\ +1-540-231-5760 \\ jcpitt@vt.edu
}

\title{
References
}

Eigler, D. M., and E. K Schweizer. 1990. Positioning Single Atoms with a Scanning Tunneling Microscope. Nature 344: 525-26.

Pitt, J. C. 2001. The Dilemma of Case Studies. Perspectives on Science: Historical, Philosophical, Social 9(4): 373-82.

Pitt, J. C. 1992. Galileo, Human Knowledge, and the Book of Nature. Dordrecht: Kluwer.

Pitt, J. C. 2005. When is an Image not an Image? Hyle: The International Journal of Philosophy of Chemistry 11 (1): 97-9 and Techne: Research in Philosophy and Technology 8(2). Reprinted in 2006 in Nanotechnology Challenges: Implications for Philosophy, Ethics and Society, ed. Joachim Schummer and Davis Baird. Singapore: World Scientific Publishing.

Pitt, J. C. 2007. Seeing Nature: Origins of Scientific Observation. In Conceptions de la Science: Hier, Aujourd'Hui et Demain, ed. R. M. Burian and J. Gayon, 27289. Brussells: Ousia.

Russell, A. 1991. The Ring. On The Anna Russell Album. 